\title{
High Ultraviolet Sensitivity of Phthalic Acid Esters with Environmental Friendliness after Modification through Pharmacophore Modeling Associated with the Solvation Effect
}

\author{
Youli Qiu', ${ }^{1,2}$ Shujing Zhang ${ }^{1}$, Yu Li ${ }^{1 *}$ \\ ${ }^{1}$ MOE Key Laboratory of Resources and Environmental System Optimization, \\ North China Electric Power University, Beijing 102206, P. R. China \\ ${ }^{2}$ Department of Environmental Engineering, North China Institute of Science and Technology, \\ Beijing 101601, P.R.China
}

Received: 17 May 2019

Accepted: 16 July2019

\begin{abstract}
We established three-dimensional quantitative structure-activity relationship (3D QSAR) pharmacophore models of ultraviolet (UV) absorption intensities for phthalic acid esters (PAEs). Substituent positions were obtained using the optimum pharmacophore model, and hydrophobic groups were used to generate PAE derivatives from the priority pollutants. The UV spectra of the PAE derivatives were calculated using the same method, and were used to screen for PAE derivatives with greatly enhanced UV absorption intensities. The derivatization and solvation effects on identification of PAEs and derivatives were considered. The results showed that the Hypol pharmacophore model had good predictive abilities and there were 14 PAE derivatives generated. The maximum UV absorption intensities of three PAE derivatives were $121.85 \%, 105.20 \%$, and $191.11 \%$ respectively, higher than those of the corresponding original PAEs. Analysis of the solvation effect showed that the UV peaks red shifted, and the degree of red shift increased with increasing solvent polarity. The minimum differential wave numbers of the UV peaks after PAE derivatization and solvation were higher than the minimum resolution of the UV spectrometer $(0.1 \mathrm{~nm})$. A two-dimensional QSAR analysis of the enhancement mechanism can reveal the derivatization and solvation enhancement. The $\log K_{\text {ow }}$ values of DNOP derivatives were predicted to lower by $25.55 \%-34.12 \%$.
\end{abstract}

Keywords: phthalic acid esters, pharmacophore model, ultraviolet spectra, derivatization and solvation, environmental monitoring

*e-mail: 731552195@qq.com 


\section{Introduction}

Phthalic acid esters (PAEs) are commonly used as plasticizers to greatly improve the strength and plasticity of plastic products [1]. They are used in numerous consumer products, food packaging materials, toys, medical devices such as blood storage bags and intravenous fluid bags, and personal care products [2]. PAEs are suspected endocrine disruptors, and can affect human reproductive health and development in both males and females [3]. PAEs can cause serious environmental damage because they are resistant to degradation in the atmosphere, water, soil, and other environmental media [4-5]. The United States Environmental Protection Agency and China have included dimethyl phthalate (DMP), dibutyl phthalate (DBP), and dioctyl phthalate (DNOP) in their lists of priority pollutants [6]. PAEs have been referred to as the next global pollutant of concern after polychlorinated biphenyls [7].

Ultraviolet (UV) spectroscopy uses the optical properties of organic compounds for content determination and structure identification [8]. The absorption peak positions and intensities are important in UV spectroscopy. The molar absorptivity $(\varepsilon)$, which is an important parameter of the absorbing material, can be used to measure the absorption intensity in UV spectra and express the absorption ability of a substance at a specific wavelength [9].

A large molar absorptivity is correlated with high absorption ability and sensitive determination, which means the molar absorptivity can be used as an index to improve detection sensitivity [10]. The UV spectra of PAEs can be obtained by experimental detection and theoretical calculation. To date, experimental studies on the UV spectra of PAEs have focused on degradation of the PAEs, and no theoretical studies have been reported. Previous studies have investigated phthalate ester degradation by direct UV irradiation [11-13], and some studies have determined the total contents of PAEs in environmental samples by UV spectrophotometry, but could not determine the exact content for each PAE [14]. Obtaining UV spectra for PAEs is time consuming, complicated, and can be harmful to the environment and human health. Quantum chemical calculations could overcome the issues associated with experimental detection [15]. Density functional theory (DFT), a classical method of electronic structure theory, can be used to calculate the molecular system and has good accuracy for calculating electron correlation energy and other aspects. DFT has been successfully applied to all aspects of quantum chemistry calculations, such as the nature of the ground state, simulation of reaction processes, and spectral analysis [16-18]. Time-dependent DFT (TDDFT) is widely used to investigate the excited states of molecules [19-21]. The polarizable continuum model, a self-consistent reaction field, is also used to model solvation effects [22].
Pharmacophore models have been widely used in drug chemistry and molecular modification of organic compounds [23], a computer-aided molecular design (CAMD) technique that usually proposes some new ideas for the optimization and design of lead compounds [24]. Studies have confirmed that pharmacophore models are useful in molecular structure modification [25]. Pharmacophore models can be used in molecular design and synthesis of derivatives from the structural information of molecules [26-27], and PAEs can be derived from the model design functions.

In this paper we constructed three-dimensional quantitative structure-activity relationship (3D QSAR) pharmacophore models of UV absorption intensities for PAEs. Positions for substituents were determined, and 14 PAE derivatives were designed. The ground state structures of the PAEs and derivatives were calculated using DFT and then the UV spectra were calculated using TD-DFT based on stable configurations obtained by ground state optimization. UV spectra of the PAEs before and after substitution were compared. To screen for PAE derivatives that greatly enhance UV absorption intensities, the transition states and the reaction energy barriers $(\Delta E)$ were calculated at the B3LYP/6-31G(d) level using DFT. The effects of solvation and derivatization on the UV absorption intensities were analyzed, and then investigated further using a two-dimensional (2D) QSAR model. Finally, based on 3D QSAR pharmacophore modeling of the logarithm of the octanol/water partition coefficient ( $\log$ Kow) values for the PAEs, $\log$ Kow values were estimated for DNOP derivatives and used to design new PAEs with lower bioconcentration factors.

\section{Material and Methods}

\section{UV Spectra and Quantum Chemical Calculations}

First, the geometries of the PAEs and derivatives in the ground state were fully optimized using DFT at the B3LYP/6-31G(d) level. Then, the UV spectra of the PAEs and derivatives were calculated at the same level using the TD-DFT [28]. Next, the reactants, products, and transition states of substitution reactions were calculated using DFT at the same level. The Gibbs free energy changes $(\Delta G)$ and reaction energy barriers $(\Delta E)$ of the substitution reactions were calculated using Eqs. (1) and (2) respectively. In addition, the UV spectra of the PAE derivatives in six different organic solvents were calculated via the polarizable continuum model [29] at the B3LYP/6-31G(d) level. The six solvents were methanol, ethanol, 1-butanol, benzene, carbon tetrachloride, and diethyl ether. The UV spectra were used to analyze the effects of solvation on the UV absorption intensities of the PAE derivatives. Finally, the quantum chemical parameters of the PAEs and derivatives were calculated at the B3LYP/6-31G(d) level [30]. The parameters calculated included the dipole 
moment ( $\mu$, Debye), energy of the highest occupied molecular orbital $\left(\mathrm{E}_{\text {номо }}, \mathrm{eV}\right)$, energy of the lowest unoccupied molecular orbital $\left(\mathrm{E}_{\mathrm{LUMO}}, \mathrm{eV}\right)$, most positive atomic partial Mulliken charge in the molecule $\left(\mathrm{q}^{+}, \mathrm{e}\right)$, most negative atomic partial Mulliken charge in the molecule $\left(\mathrm{q}^{-}, \mathrm{e}\right)$, and most positive partial Mulliken charge in the $\mathrm{H}$ atom $\left(\mathrm{qH}^{+}\right.$, e). All calculations were performed using Gaussian 09 [31].

$$
\begin{gathered}
\Delta G=\sum G(\text { product })-\sum G(\text { reactant }), \\
\Delta E=E(\text { transition state })-\sum E(\text { reactant }) .
\end{gathered}
$$

\section{D QSAR Pharmacophore Model}

The 3D QSAR pharmacophore models were constructed using the HypoGen module of Accelrys Discovery Studio (Version 2.5, www.accelrys.com) [32]. The diverse conformation option was applied and 255 conformations were generated using the BEST generation module at an energy threshold of $20 \mathrm{kcal} / \mathrm{mol}$. The minimum and maximum counts for all the features were set to one and five, respectively [33]. The features considered for the various hypotheses were hydrogen bond acceptor, hydrogen bond donor, hydrophobic, hydrophobic aliphatic, and ring aromatic.

The qualities of the established pharmacophore models were mainly validated based on cost analysis and consideration of determinant factors, such as configuration cost, root-mean-square (RMS), correlation coefficient $\left(\mathrm{R}^{2}\right)$, error, and fit value. The optimum pharmacophore model will have a high correlation coefficient, low RMS deviation, a total cost of the generated hypothesis close to the fixed cost and distant from the null cost [34], and a configuration value of less than $17[35]$.

\section{D QSAR Model of UV Absorption Intensities}

To facilitate 2D QSAR analysis, the logarithms of the UV absorption intensities of PAEs and PAE derivatives were used as the dependent variables in the 2D QSAR model. Through studying literature [36-38], we found that $\mathrm{q}^{-}, \mathrm{q}^{+}, \mathrm{qH}^{+}, \mathrm{E}_{\text {номо }}, \mathrm{E}_{\text {Lumo }}$ and $\mu$ were usually selected as independent variables to construct the 2D-QSAR model of properties of compounds. Therefore, the independent variables were the six quantum chemical parameters in this study. The 2D QSAR model of UV absorption intensities was constructed after PAE derivatization and solvation based on quantitative parameters, and was used to investigate the mechanism for enhancing UV absorption intensities by derivatization and solvation.

\section{Results and Discussion}

3D QSAR Pharmacophore model of UV Spectra Intensities

Nine ligand-based pharmacophore models were developed using a training set of 16 PAEs and their UV absorption intensities. A test set of four PAEs was used to validate the pharmacophore model. The cost, $\mathrm{R}^{2}$, and RMS deviation for each hypothesis are presented in Table 1.

Among these models, the Hypol model showed the highest $\mathrm{R}^{2}$ of 0.79 and the lowest RMS value of 0.14 (Table 1). The total cost, fixed cost, and null cost of the Hypol model were 69.72, 69.57, and 154.22, respectively. The total cost was distant from the null cost and close to the fixed cost. The configuration cost of the Hypol model was $14.63(<17)$, indicating that it was an effective model.

Table 1. Statistical parameters for the nine pharmacophore models of phthalic acid ester ultraviolet absorption intensities.

\begin{tabular}{|c|c|c|c|c|c|}
\hline Hypo No. & Total cost & $\begin{array}{c}\text { Cost } \\
\text { difference }\end{array}$ & RMS & $\mathrm{R}^{2}$ & Features \\
\hline 1 & 69.72 & 0.15 & 0.14 & 0.79 & HBA HBA H \\
\hline 2 & 69.72 & 0.15 & 0.14 & 0.78 & HBA HBA H \\
\hline 3 & 69.77 & 0.20 & 0.16 & 0.79 & HBA HBA RA \\
\hline 4 & 69.78 & 0.21 & 0.16 & 0.76 & HBA HBA H \\
\hline 5 & 69.79 & 0.22 & 0.17 & 0.70 & HBA HBA RA \\
\hline 6 & 69.83 & 0.26 & 0.18 & 0.70 & HBA HA RA \\
\hline 7 & 69.84 & 0.27 & 0.18 & 0.57 & HBA H H \\
\hline 8 & 69.84 & 0.27 & 0.18 & 0.59 & HBA HBA H \\
\hline 9 & 69.85 & 0.28 & 0.19 & Null cost & HBA HA H \\
\hline Configuration & 14.63 & Fixed cost & 69.57 & 154.22 \\
\hline
\end{tabular}

Abbreviations: HBA, hydrogen bond acceptor; H, hydrophobic; HA, hydrophobic aromatic; RA, ring aromatic 
Table 2. Statistical data for the 16 phthalic acid esters in the training set based on the Hypo1 model.

\begin{tabular}{|c|c|c|c|c|}
\hline PAEs & Fit Value & $\begin{array}{l}\text { Est ultraviolet intensity } \\
\left(\mathrm{L} \cdot \mathrm{mol}^{-1} \cdot \mathrm{cm}^{-1}\right)\end{array}$ & $\begin{array}{l}\text { Act ultraviolet intensity } \\
\left(\mathrm{L} \cdot \mathrm{mol}^{-1} \cdot \mathrm{cm}^{-1}\right)\end{array}$ & Error \\
\hline DIPrP & 6.01 & 5273.46 & 4162.78 & 1.27 \\
\hline DBP & 5.75 & 9581.11 & 11055.80 & -1.15 \\
\hline DPrP & 5.80 & 8605.67 & 7457.30 & 1.15 \\
\hline ВMPP & 5.79 & 8751.18 & 7833.13 & 1.12 \\
\hline BBP & 5.91 & 9637.73 & 9916.44 & -1.49 \\
\hline DEHP & 5.78 & 8963.89 & 8365.72 & 1.07 \\
\hline DINP & 5.78 & 8983.33 & 8605.24 & 1.04 \\
\hline DNOP & 5.77 & 9322.96 & 9009.74 & 1.03 \\
\hline DNP & 5.78 & 9129.00 & 10518.90 & -1.15 \\
\hline DHP & 5.77 & 9155.17 & 10658.60 & -1.16 \\
\hline DIDP & 5.79 & 8851.28 & 8418.51 & 1.05 \\
\hline DIHxP & 5.69 & 11081.70 & 12914.10 & -1.17 \\
\hline DIBP & 5.77 & 9245.37 & 7919.53 & 1.17 \\
\hline DPP & 5.74 & 9938.55 & 10470.00 & -1.05 \\
\hline DMP & 5.73 & 10064.80 & 10555.90 & -1.05 \\
\hline DEP & 5.74 & 9971.64 & 9477.79 & 1.05 \\
\hline
\end{tabular}

Statistical data for the 16 PAEs in the training set based on the Hypol model are shown in Table 2. The error values were less than 2 [39], which was in the range of allowable error for the 16 PAEs. These results confirm the reliability of the Hypol model. The $\mathrm{R}^{2}$ for the training set given by the Hypol model was 0.79, indicating a good correlation by linear regression.

\section{Validation of the Pharmacophore Model}

Validation of the Hypol pharmacophore model was performed using the test set. The four PAEs in the test set were imported into the Hypo Gen module, and diverse conformers were built in the same manner as for training set compounds. The test set results are shown in Table 3. Analyses of the estimated UV absorption intensities of the test set compounds gave an error of less than two. Therefore, the Hypol model is suitable for the training set PAEs and the external PAEs.

\section{Determining Substitution Positions of PAE Derivatives}

The Hypo 1 model and priority pollutants DMP, DBP, and DNOP were used to determine the appropriate positions for substituents for PAE derivatization. Hypo1 contained two hydrogen bond acceptors (green) and one hydrophobic group (blue) (Fig. 1). The hydrogen bond acceptor features cover two carbonyls, and the hydrophobic group was located at the 4-position of benzene ring. Introduction of a hydrophobic group in this position could affect the UV absorption intensities for the PAEs [40]. Therefore, the 3D QSAR pharmacophore model can be used to conclude that the position of hydrophobic substituents may be effective for changing the UV absorption intensities of PAEs.

Table 3. Experimental and estimated ultraviolet intensities for the four phthalic acid esters in the test set based on the pharmacophore model Hypo1.

\begin{tabular}{|c|c|c|c|c|}
\hline PAEs & Fit Value & $\begin{array}{c}\text { Est ultraviolet intensity } \\
\left(\mathrm{L} \cdot \mathrm{mol}^{-1} \cdot \mathrm{cm}^{-1}\right)\end{array}$ & $\begin{array}{c}\text { Act ultraviolet intensity } \\
\left(\mathrm{L} \cdot \mathrm{mol}^{-1} \cdot \mathrm{cm}^{-1}\right)\end{array}$ & Error \\
\hline DIOP & 5.76 & 9380.64 & 9412.94 & 1.00 \\
\hline DUP & 5.78 & 8954.88 & 8472.45 & 1.06 \\
\hline DTDP & 5.75 & 9713.39 & 10478.52 & -0.93 \\
\hline DIHP & 5.74 & 7936.75 & 7761.12 & 1.02 \\
\hline
\end{tabular}



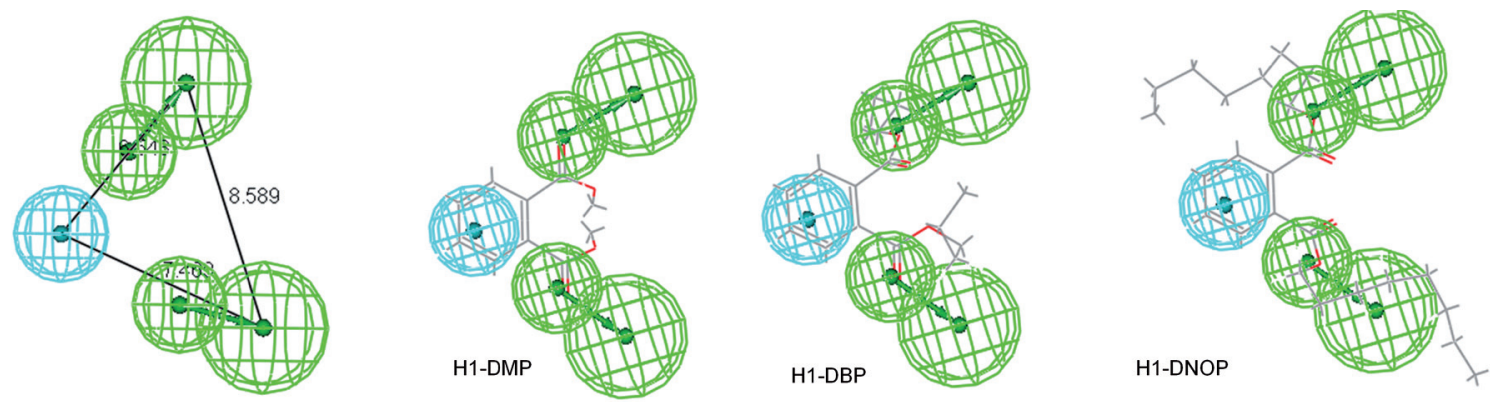

Fig. 1. 3D spatial relationship and Hypo1 aligning with DMP, DBP and DNOP.

\section{PAE Derivatization Using} the Pharmacophore Model

The following six hydrophobic groups were selected as substituents: ethyl $\left(-\mathrm{CH}_{2} \mathrm{CH}_{3}\right)$, nitro $\left(-\mathrm{NO}_{2}\right)$, chloro $(-\mathrm{Cl})$, bromo (-Br), mercapto (-SH), and methoxy $\left(-\mathrm{OCH}_{3}\right)$. The 18 PAE derivatives were generated based on the UV absorption intensities in pharmacophore model Hypol, the screening basis in the first step of PAE derivatives was UV absorption intensities, the intensity values of the four derivatives are reduced, so the final selection is 14 PAE derivatives, including six DMP derivatives, five DBP derivatives, and three DNOP derivatives. The UV absorption intensities and frequencies of the fourteen PAE derivatives are given in Table 4. The calculated frequencies of the PAE derivatives showed no imaginary frequencies (Table 4), which means that the optimized configurations of the PAEs and derivatives were stable [41]. The UV absorption intensities of the PAE derivatives showed an increasing tendency. Compared with DMP, DBP, and DNOP, the DMP, DBP and DNOP derivatives had absorption intensities that were 6.02-121.85\%, 6.16-105.20\%, and 19.36-191.11\% higher, respectively. For the -SH derivatives, the UV absorption intensities of DMP-SH, DBP-SH, and DNOP-SH were $121.85 \%$, $105.20 \%$, and $191.11 \%$ higher, respectively. These results showed that PAE derivatization based on the Hypol pharmacophore model greatly improved the UV detection sensitivity and greatly reduced the detection limit.

Calculating the Energy Barrier for the PAE Derivatization Reaction

Although the PAE derivatives from the Hypol pharmacophore model can enhance the UV spectra, which is beneficial for environmental monitoring, the degree of difficulty of each PAE derivatization reaction needs to be considered. We evaluated possible substitution reaction pathways, and used these to screen for PAEs that would be easy to prepare. The $\Delta G$ values

Table 4. Ultraviolet absorption intensities and frequencies of the phthalic acid ester derivatives.

\begin{tabular}{|c|c|c|c|c|}
\hline PAEs & PAE derivatives & Ultraviolet intensity $\left(\mathrm{L} \cdot \mathrm{mol}^{-1} \cdot \mathrm{cm}^{-1}\right)$ & Enhancement degree (\%) & Frequency $\left(\mathrm{cm}^{-1}\right)$ \\
\hline \multirow{6}{*}{ DMP } & DMP-Br & 11191.37 & 6.02 & 33.23 \\
\hline & DMP- $\mathrm{CH}_{2} \mathrm{CH}_{3}$ & 11961.38 & 13.31 & 32.93 \\
\hline & DMP-Cl & 11231.06 & 6.40 & 34.10 \\
\hline & $\mathrm{DMP}-\mathrm{NO}_{2}$ & 16469.03 & 56.02 & 31.67 \\
\hline & $\mathrm{DMP}-\mathrm{OCH}_{3}$ & 20311.13 & 92.41 & 53.76 \\
\hline & DMP-SH & 23418.20 & 121.85 & 52.95 \\
\hline \multirow{5}{*}{ DBP } & DBP-Br & 11736.84 & 6.16 & 12.71 \\
\hline & $\mathrm{DBP}-\mathrm{CH}_{2} \mathrm{CH}_{3}$ & 12676.88 & 14.66 & 20.54 \\
\hline & $\mathrm{DBP}-\mathrm{Cl}$ & 12050.84 & 9.00 & 19.76 \\
\hline & $\mathrm{DBP}_{-} \mathrm{OCH}_{3}$ & 17953.55 & 62.39 & 18.94 \\
\hline & DBP-SH & 22686.78 & 105.20 & 15.20 \\
\hline \multirow{3}{*}{ DNOP } & DNOP-CH $\mathrm{CH}_{3}$ & 10754.11 & 19.36 & 7.53 \\
\hline & $\mathrm{DNOP}-\mathrm{NO}_{2}$ & 19748.34 & 119.19 & 5.26 \\
\hline & DNOP-SH & 26227.85 & 191.11 & 5.35 \\
\hline
\end{tabular}


Table 5. Energy barriers of the substitution reaction pathways.

\begin{tabular}{|c|c|c|c|c|}
\hline Reaction paths & Reactant (Hartree) & TS (Hartree) & $\Delta \mathrm{E}$ (Hartree) & $\Delta \mathrm{E}(\mathrm{kJ} / \mathrm{mol})$ \\
\hline Path1 (DMP substituted by -Br) & -3259.65 & -3259.59 & $5.67 \times 10^{-2}$ & 148.85 \\
\hline Path 2 (DMP substituted by- $\mathrm{CH}_{2} \mathrm{CH}_{3}$ ) & -767.13 & -767.11 & $2.70 \times 10^{-2}$ & 69.93 \\
\hline Path3 (DMP substituted by-Cl) & -1148.13 & -1148.09 & $4.32 \times 10^{-2}$ & 113.31 \\
\hline Path4 (DMP substituted by- $\mathrm{NO}_{2}$ ) & -893.07 & -892.99 & $7.59 \times 10^{-2}$ & 199.27 \\
\hline Path5 (DMP substituted by-OCH ${ }_{3}$ ) & -803.06 & -803.02 & $3.52 \times 10^{-2}$ & 92.31 \\
\hline Path6 (DMP substituted by-SH) & -1086.73 & -1086.68 & $5.50 \times 10^{-2}$ & 144.51 \\
\hline Path7 (DBP substituted by-Br) & -3495.48 & -3495.47 & $6.17 \times 10^{-3}$ & 16.20 \\
\hline Path8 (DBP substituted by- $\mathrm{CH}_{2} \mathrm{CH}_{3}$ ) & -1003.03 & -1003.00 & $2.51 \times 10^{-2}$ & 66.00 \\
\hline Path9 (DBP substituted by-Cl) & -1384.02 & -1383.96 & $5.42 \times 10^{-2}$ & 142.32 \\
\hline Path10 (DBP substituted by- $\mathrm{OCH}_{3}$ ) & -1038.90 & -1038.90 & $1.57 \times 10^{-3}$ & 4.11 \\
\hline Path11 (DBP substituted by-SH) & -1322.62 & -1322.56 & $6.15 \times 10^{-2}$ & 161.34 \\
\hline Path12 (DNOP substituted by- $\mathrm{CH}_{2} \mathrm{CH}_{3}$ ) & -1317.54 & -1317.52 & $2.71 \times 10^{-2}$ & 71.14 \\
\hline Path13 (DNOP substituted by- $\mathrm{NO}_{2}$ ) & -1443.47 & -1443.39 & $7.51 \times 10^{-2}$ & 197.04 \\
\hline Path14 (DNOP substituted by-SH) & -1637.04 & -1637.08 & $5.66 \times 10^{-2}$ & 148.52 \\
\hline
\end{tabular}

of the substitution reaction pathways for the 14 PAEs were all negative (Table S1), and all 14 PAE derivatives could be generated spontaneously [42]. To compare the degrees of difficulty for the 14 substitution reactions, the energy barriers $(\Delta \mathrm{E})$ were calculated (Table 5).

The energy barrier for path 2 for DMP was the lowest (Table 5), and this was the most favorable pathway for DMP. Similarly, path 10 was the most favorable for DBP, and path 12 was the most favorable for DNOP. By comparing the reaction pathways, we ordered the 14 substitution reactions as follows: $-\mathrm{CH}_{2} \mathrm{CH}_{3}>-\mathrm{OCH}_{3}>-\mathrm{Cl}>-\mathrm{SH}>-\mathrm{Br}>-\mathrm{NO}_{2}$ for DMP derivatives, $-\mathrm{OCH}_{3}>-\mathrm{Br}>-\mathrm{CH}_{2} \mathrm{CH}_{3}>-\mathrm{Cl}>-\mathrm{SH}$ for DBP derivatives, and $-\mathrm{CH}_{2} \mathrm{CH}_{3}>-\mathrm{SH}>-\mathrm{NO}_{2}$ for DNOP derivatives. Taking into consideration the enhancement in UV absorption intensity and the degree of difficulty for each substitution reaction, DMP-OCH, $\mathrm{DBP}_{3} \mathrm{OCH}_{3}$, and DNOP-SH derivatives could be used to enhance the UV spectra of DMP, DBP, and DNOP, respectively.

\section{Solvation Enhancement Effect on the UV Spectra}

According to their polarities, six organic solvents were selected from among common solvents to analyze the effect of solvation on the UV spectra of the PAE derivatives [43]. The polar solvents were methanol, ethanol, and 1-butanol, and the nonpolar solvents were benzene, carbon tetrachloride, and diethyl ether. The polarities were in the order methanol $>$ ethanol $>$ 1-butanol $>$ diethyl ether $>$ benzene $>$ carbon tetrachloride. The solvation effects were further

Table 6. Effect of solvation on the ultraviolet spectra of phthalic acid ester derivatives.

\begin{tabular}{|c|c|c|c|c|c|c|c|}
\hline PAE derivatives & Ultraviolet spectra & Methanol & Ethanol & 1 -Butanol & Diethyl ether & Benzene & Carbon tetrachloride \\
\hline \multirow{2}{*}{ DMP-OCH $_{3}$} & Enhancement degree (\%) & 81.48 & 80.28 & 79.08 & 76.9 & 38.15 & 37.43 \\
\cline { 2 - 8 } & $\Delta \lambda_{\max }(\mathrm{nm})$ & 15.46 & 15.25 & 14.58 & 15.05 & 7.26 & 7.13 \\
\hline \multirow{2}{*}{ DMP-SH } & Enhancement degree (\%) & 60.61 & 59.66 & 57.96 & 42.55 & 28.13 & 27.58 \\
\cline { 2 - 9 } & $\Delta \lambda_{\max }(\mathrm{nm})$ & 16.40 & 16.11 & 15.55 & 10.77 & 6.71 & 6.55 \\
\hline \multirow{2}{*}{ DBP-OCH $_{3}$} & Enhancement degree (\%) & 90.32 & 88.78 & 86.00 & 59.43 & 32.78 & 31.76 \\
\cline { 2 - 9 } & $\Delta \lambda_{\max }(\mathrm{nm})$ & 30.43 & 30.19 & 29.82 & 26.96 & 24.53 & 24.52 \\
\hline \multirow{2}{*}{ DBP-SH } & Enhancement degree (\%) & 76.66 & 75.52 & 73.42 & 54.48 & 36.11 & 35.41 \\
\cline { 2 - 9 } & $\Delta \lambda_{\max }(\mathrm{nm})$ & 15.65 & 15.39 & 14.91 & 10.56 & 7.08 & 6.93 \\
\hline \multirow{2}{*}{ DNOP-SH } & Enhancement degree (\%) & 51.45 & 50.68 & 49.31 & 36.82 & 24.76 & 24.32 \\
\cline { 2 - 8 } & $\Delta \lambda_{\max }(\mathrm{nm})$ & 16.91 & 16.59 & 15.97 & 10.73 & 6.62 & 6.45 \\
\hline
\end{tabular}


investigated using DMP-OCH${ }_{3}$, DMP-SH, DBP-SH, $\mathrm{DBP}_{-} \mathrm{OCH}_{3}$, and DNOP-SH. The five PAE derivatives are representative, their ultraviolet absorption intensity enhancement effects are remarkable and the substitution reactions are easy to occur. And the changes in the UV absorption intensities and maximum absorption wavelengths $\left(\lambda_{\max }\right)$ on derivatization were evaluated. The UV absorption intensities of the PAE derivatives were maximized in methanol, and minimized in carbon tetrachloride (Table 6). The UV absorption intensities of the PAE derivatives in the six solvents were in the order methanol $>$ ethanol $>$ 1-butanol $>$ diethyl ether $>$ benzene $>$ carbon tetrachloride. This order is consistent with increasing solvent polarity. When we compared the maximum absorption wavelengths for the PAEs in the solvents and the gas phase, the maximum absorption wavelengths of the PAE derivatives were red shifted in the solvents. Furthermore, as the solvent polarity increased, the magnitude of the red shift also increased.

\section{Identifying PAEs from UV Spectra after Derivatization}

The minimum differential wave numbers of the UV spectra for the PAEs and their derivatives are shown in Table S2. The minimum differential wave numbers of 12 of the PAEs before derivatization were higher than the minimum resolution of UV spectra detection instrument $(0.10 \mathrm{~nm})$ [44]. The minimum differential wave numbers of the other four PAEs were less than $0.10 \mathrm{~nm}$. When DMP, DBP, and DNOP were replaced by derivatives, the minimum differential wave numbers of all the PAEs and derivatives were greater than $0.10 \mathrm{~nm}$. Therefore, PAE derivatization facilitates identification of PAEs by enhancing the UV spectra.

\section{Identifying PAEs from UV Spectra after Solvation}

The minimum differential wave numbers of $\mathrm{DMP}_{-} \mathrm{OCH}_{3}, \mathrm{DMP}_{-\mathrm{SH}}$ DBP-SH, DBP-OCH $\mathrm{CH}_{3}$ and DNOP-SH in the gas phase were $2.83 \mathrm{~nm}, 0.63 \mathrm{~nm}$, $16.40 \mathrm{~nm}, 0.63 \mathrm{~nm}$, and $1.69 \mathrm{~nm}$, respectively. These results were higher than the minimum resolution of the UV spectrometer $(0.10 \mathrm{~nm})$. The UV spectra of five of the PAE derivatives in six solvents are shown in Fig. 2. After solvation, the minimum differential wave numbers of these five PAE derivatives were higher than the minimum resolution of the UV spectrometer $(0.10 \mathrm{~nm})$. Therefore, solvation can enhance the UV absorption intensities of PAE derivatives and allow for effective identification.

\section{D QSAR Analysis of the Mechanism for Enhancing UV Absorption Intensities}

The UV spectra of DMP, DBP, and DNOP after derivatization and solvation are shown in Figure 3. First, the UV absorption intensities of the PAE derivatives were compared with PAEs in the gas phase. This showed that the UV absorption intensities of the PAE derivatives were greater than the UV absorption intensities of the PAEs. The UV absorption intensities of the PAE derivatives in solvents were greater than those of the derivatives in the gas phase. Generally, PAE derivatization and solvation can increase the UV absorption intensities.

To further explore the mechanism for enhancing UV absorption intensities, the 2D QSAR model of UV absorption intensities was adopted. The 2D QSAR model relies on quantum chemical calculations to
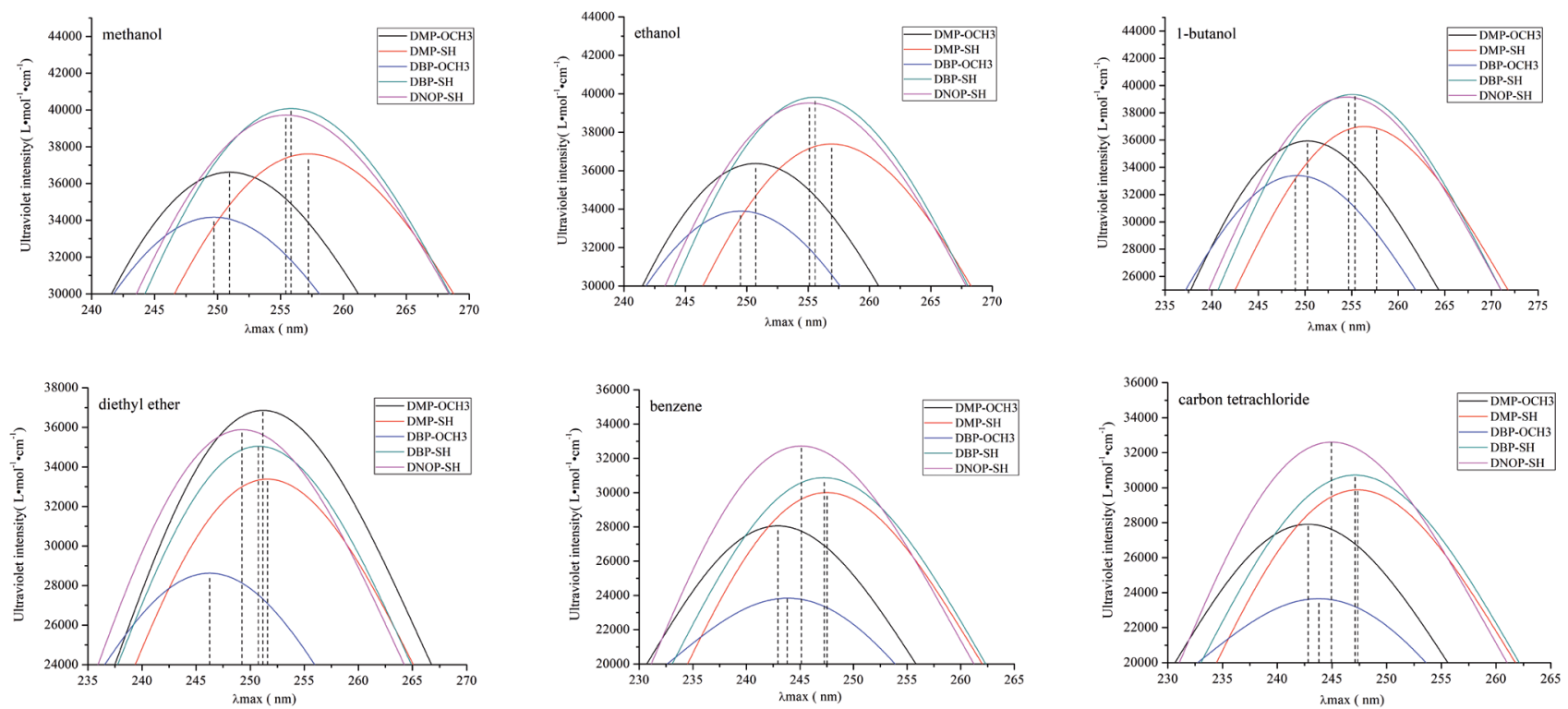

Fig. 2. Ultraviolet spectra of five phthalic acid ester derivatives in six solvents. 

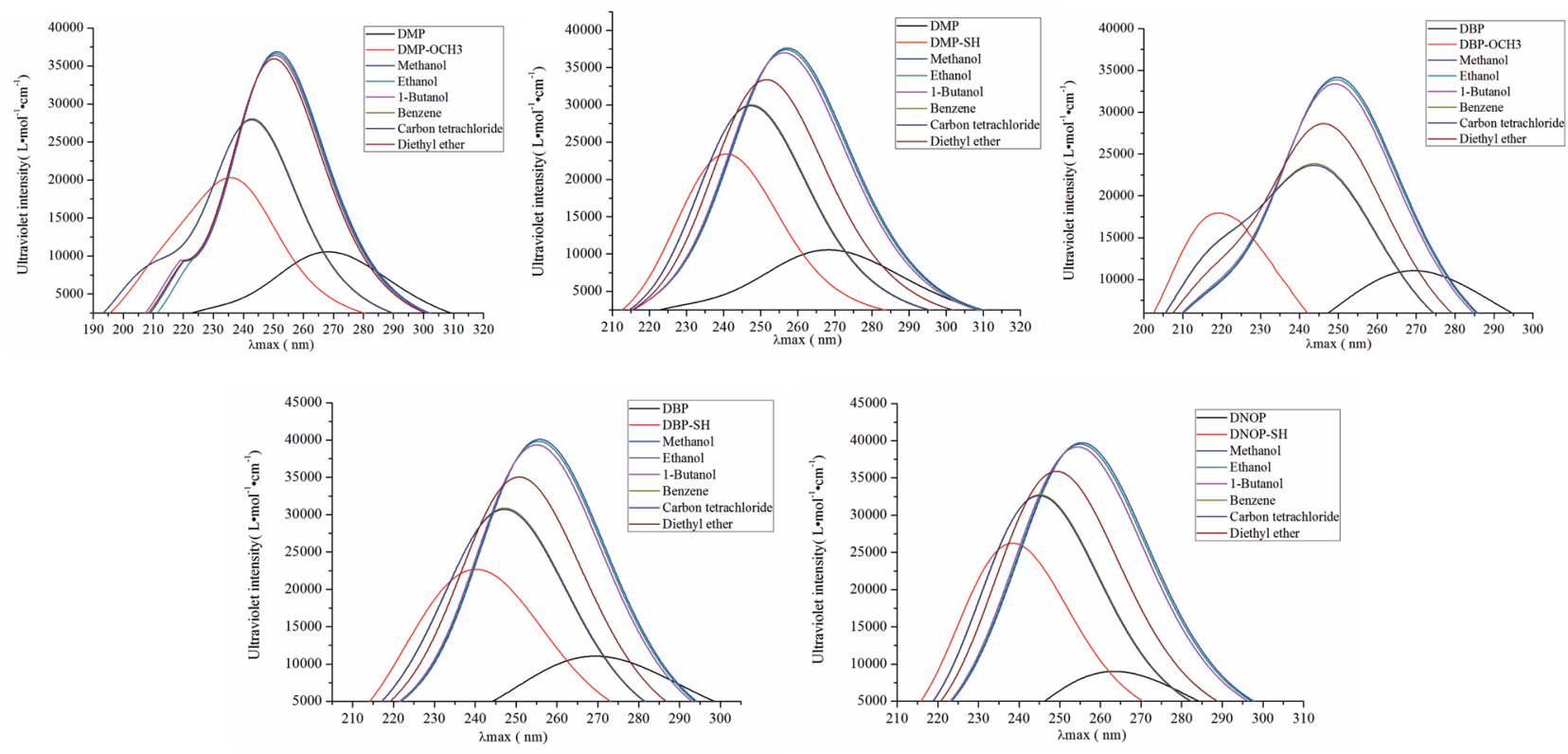

Fig. 3. Ultraviolet spectra of DMP, DBP, DNOP derivatization and salvation.

obtain molecular structure parameters, and quantum chemical parameters are independent of experimental measurements and have definite physical significance, which is beneficial to exploring the mechanisms of pollutants [45]. The logarithms of the UV absorption intensities of the PAEs and their derivatives were used as the dependent variables in the QSAR model of UV absorption intensities, and the independent variables were the six quantum chemical parameters. The 2D QSAR model of UV absorption intensities was constructed based on quantitative parameters after PAE derivatization and solvation. The following equations were used to predict the PAE UV absorption intensities based on quantitative parameters:

$$
\begin{gathered}
\log (\mathrm{UV} \text { intensity })=-0.715-0.006 \mu-0.353 E_{\text {Hомо }}+ \\
0.079 E_{\text {LUMO }}-3.074 q^{-}+0.790 q^{+}+2.508 q H^{+}
\end{gathered}
$$

$$
\begin{aligned}
& \log (\mathrm{UV} \text { intensity })=4.297-0.023 \mu+0.533 E_{\text {номо }} \\
& \quad-0.355 E_{\text {LUMO }}-7.213 q^{-}-1.886 q^{+} 3.406 q H^{+}
\end{aligned}
$$

$$
\begin{aligned}
& \log (\mathrm{UV} \text { intensity })=-3.718+0.014 \mu-0.938 E_{\text {HOMO }} \\
& \quad-0.188 E_{\text {LUMO }}+0.126 q^{-}+0.870 q^{+}+7.923 q H^{+}
\end{aligned}
$$

Equation (3) was used for the 16 PAEs with $\mathrm{R} 2=0.847>0.8$, standard deviation $(\mathrm{SD})=0.026, \mathrm{~F}$ statistic $(\mathrm{F})=3.824$, and $\mathrm{Sig}=0.036<0.05$. Equation (4) was used for 14 PAE derivatives with $\mathrm{R}^{2}=0.918$ $>0.8, \mathrm{SD}=0.054, \mathrm{~F}=13.063$, and $\mathrm{Sig}=0.002<0.05$. Equation (5) was used for five PAE derivatives in six solvents with $\mathrm{R}^{2}=0.896>0.8, \mathrm{SD}=0.031, \mathrm{~F}=15.647$, and Sig $=0.000<0.05$. All the coefficients were checked by statistical analysis, which showed that the models had good fits and prediction abilities [46], and could suitably explain the mechanism for enhancement of UV absorption intensities. The parameter coefficients of $\mathrm{E}_{\text {LUMO }}, \mathrm{q}^{+}$, and $\mathrm{qH}^{+}$were positive, and those of $\mu, \mathrm{E}_{\text {номо }}$, and $\mathrm{q}^{-}$were negative (Eq. (3)). These results illustrate that the energy of the lowest unoccupied molecular orbital, most positive atomic partial Mulliken charge in the molecule, and most positive partial Mulliken charge in the $\mathrm{H}$ atom have positive effects on the UV absorption intensities before PAE derivatization. The dipole moment, the energy of the highest occupied molecular orbital, and the most negative atomic partial Mulliken charge in the molecule have negative effects before derivatization. Similarly, Eq. (4) showed that the energy of the highest occupied molecular orbital and the most positive partial Mulliken charge in the $\mathrm{H}$ atom had positive effects on the UV spectra intensities after PAE derivatization. The dipole moment, the energy of the lowest unoccupied molecular orbital, the most negative atomic partial Mulliken charge in the molecule and the most positive atomic partial Mulliken charge in the molecule had negative effects after derivatization. In Eq. (5), the dipole moment, the most negative atomic partial Mulliken charge in the molecule, the most positive atomic partial Mulliken charge in the molecule, and the most positive partial Mulliken charge in the $\mathrm{H}$ atom had positive effects on the UV absorption intensities after solvation of the PAE derivatives. The energy of the highest occupied molecular orbital and the energy of the lowest unoccupied molecular orbital had negative effects after solvation. The results of the three equations indicated that the enhancement of the UV spectra by PAE derivatization was caused by the effects of the energy of the highest occupied molecular orbital, energy of the lowest unoccupied molecular orbital, and the most positive atomic partial Mulliken charge in 
Table 7. Nine pharmacophore models for phthalic acid ester $\log K_{\text {ow }}$ values determined using Hypo Gen.

\begin{tabular}{|c|c|c|c|c|c|}
\hline Hypo No. & Total cost & Cost difference & RMS & $\mathrm{R}^{2}$ & Features \\
\hline 1 & 54.66 & 0.49 & 0.28 & 0.89 & HBA H RA \\
\hline 2 & 54.69 & 0.52 & 0.29 & 0.88 & HBA HA RA \\
\hline 3 & 54.71 & 0.54 & 0.30 & 0.87 & HBA HBA H \\
\hline 4 & 54.73 & 0.56 & 0.30 & 0.88 & HBA H RA \\
\hline 5 & 54.73 & 0.56 & 0.30 & 0.86 & HBA HA RA \\
\hline 6 & 54.77 & 0.60 & 0.31 & 0.86 & HBA HBA H \\
\hline 7 & 54.77 & 0.60 & 0.32 & 0.83 & HBA HBA HA \\
\hline 8 & 54.79 & 0.62 & 0.32 & 0.82 & HBA HBA HA \\
\hline 9 & 54.82 & 0.65 & 0.33 & 0.84 & HBA HA RA \\
\hline Configuration & 12.68 & Fixed cost & 54.17 & Null cost & 142.23 \\
\hline
\end{tabular}

the molecule. By contrast, the solvation enhancement effects on the PAE derivatives were mainly caused by the dipole moment, the energy of the highest occupied molecular orbital, the most negative atomic partial Mulliken charge in the molecule and the most positive partial Mulliken charge in $\mathrm{H}$ atom.

\section{Predicting $\log K_{\text {ow }}$ Values for PAE Derivatives}

The $K_{\text {ow }}$ is an important parameter used to evaluate the distribution of organic pollutants in environmental matrices. In the present study, the $\log K_{\text {ow }}$ was taken as an index of PAE bioconcentration. The $\log K_{\text {ow }}$ experimental values of 15 PAEs were obtained directly from the literature [47]. The whole data set (15 PAEs) was divided into a training set (12 PAEs) for 3D QSAR pharmacophore model generation and a test set (3 PAEs) for model validation. Nine pharmacophore models of PAE $\log K_{\text {ow }}$ were evaluated (Table 7).

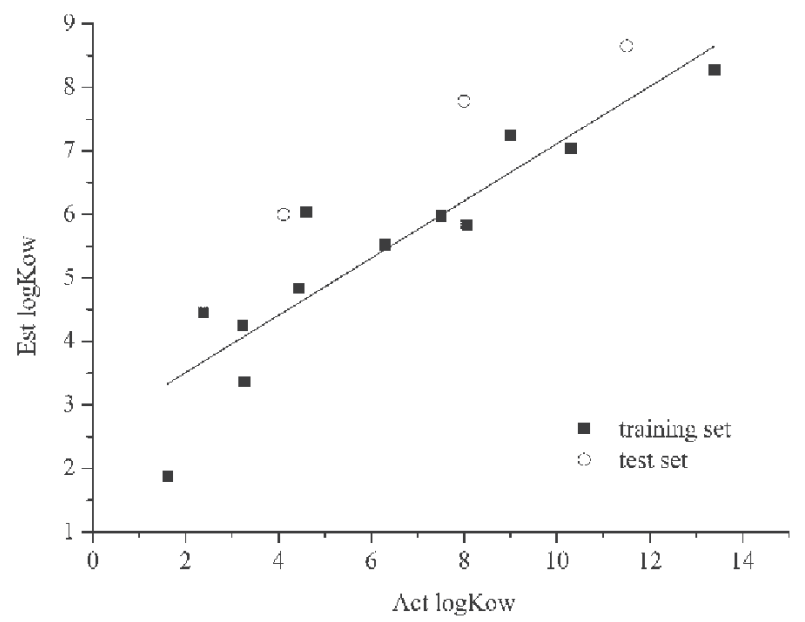

Fig. 4. Experimental $\log \mathrm{K}_{\mathrm{ow}}$ values and those predicted using the pharmacophore model Hypo1.
The Hypol model showed the highest $\mathrm{R}^{2}$ of 0.89 and the minimum RMS value of 0.28 , the total cost value of 54.66 was distant from the null cost and close to the fixed cost. The configuration cost of the Hypol model was $12.38(<17)$, indicating that it was an effective model.

The test set was prepared using the same protocol as for the training set and used to determine whether the hypothesis was able to predict the $\log$ Kow values of test compounds other than the training set molecules. The $\log K_{\text {ow }}$ values of 15 PAEs predicted using the Hypol model are listed in Table S3 (Supporting File). The test set of four PAEs was used to further validate the reliability and applicability of the Hypol model. The correlations between the experimental and predicted $\log K_{\text {ow }}$ values are depicted in Fig. 4. Further analysis of the $\log K_{\text {ow }}$ predicted by the Hypol model revealed good linear dependence $\left(\mathrm{R}^{2}\right.$ of 0.81$)$ among the experimental values and predicted values (Fig. 4).

The $\log K_{\text {ow }}$ values of the priority pollutants DMP, DBP, and DNOP are 1.61, 4.45, and 8.06 respectively. The $\log K_{\text {ow }}$ value of DNOP is greater than five, which means that DNOP is a persistent organic pollutant [48]. The $\log$ Kow values of DNOP derivatives were predicted using the 3D QSAR pharmacophore model of $\log K_{\text {ow }}$ values (Table 8 ). The $\log K_{\mathrm{ow}}$ values of DMP derivatives are higher than those of DMP, but it is still lower than 5 . The $\log K_{\text {ow }}$ values of DBP derivatives are $44.71 \%$ lower than DBP, and the maximum increase is $7.85 \%$, which is also lower than 5 . The $\log K_{\text {ow }}$ values of the DNOP derivatives were much lower than those of DNOP, with the $\log K_{\text {ow }}$ of DNOP-SH reduced to 5.31, which is close to five. Therefore, DNOP derivatives could be more environmentally friendly than DNOP. This method provides a way to design new PAEs with lower bioconcentration factors. 
Table 8. Predicted logKow values of the PAE derivatives from the pharmacophore model

\begin{tabular}{|c|c|c|c|c|}
\hline PAEs & PAE derivatives & Fit value & Est $\log K_{\text {ow }}$ & Change rate $(\%)$ \\
\hline \multirow{6}{*}{ DMP } & DMP-Br & 5.84 & 1.89 & 17.39 \\
\hline & DMP- $\mathrm{CH}_{2} \mathrm{CH}_{3}$ & 5.84 & 1.91 & 18.35 \\
\hline & DMP-Cl & 5.84 & 1.89 & 17.44 \\
\hline & $\mathrm{DMP}_{-} \mathrm{NO}_{2}$ & 5.84 & 1.90 & 17.72 \\
\hline & $\mathrm{DMP}^{-\mathrm{OCH}_{3}}$ & 5.84 & 1.90 & 17.95 \\
\hline & DMP-SH & 5.87 & 1.78 & 10.70 \\
\hline \multirow{5}{*}{ DBP } & $\mathrm{DBP}-\mathrm{Br}$ & 5.44 & 4.80 & 7.85 \\
\hline & $\mathrm{DBP}-\mathrm{CH}_{2} \mathrm{CH}_{3}$ & 5.48 & 4.37 & -1.69 \\
\hline & DBP-Cl & 5.73 & 2.46 & -44.71 \\
\hline & $\mathrm{DBP}-\mathrm{OCH}_{3}$ & 5.58 & 3.48 & -21.74 \\
\hline & DBP-SH & 5.47 & 4.46 & 0.15 \\
\hline \multirow{3}{*}{ DNOP } & $\mathrm{DNOP}-\mathrm{CH}_{2} \mathrm{CH}_{3}$ & 5.38 & 5.47 & -32.12 \\
\hline & DNOP-NO & 5.34 & 6.00 & -25.55 \\
\hline & DNOP-SH & 5.39 & 5.31 & -34.13 \\
\hline
\end{tabular}

\section{Conclusions}

Fourteen PAE derivatives were designed using the priority pollutants DMP, DBP, and DNOP and a 3D QSAR pharmacophore model. The UV spectra of the PAEs and their derivatives were calculated at the same level using TD-DFT. The UV absorption intensities of DMP-SH, DBP-SH, and DNOP-SH were $121.85 \%, 105.20 \%$, and $191.11 \%$ higher than those of DMP, DBP, and DNOP. The structures of the PAE derivatives were stable (frequencies $>0$ ), and the UV absorption intensities of the PAE derivatives were greatly enhanced. To evaluate the effect of solvation on UV spectra enhancement, five PAE derivatives were screened for UV absorption intensities and the degree of difficulty of each substitution reaction was considered. The UV absorption intensities and degree of red shift of the PAE derivatives increased with increasing solvent polarity. The minimum differential wave numbers of the UV peaks after PAE derivatization and solvation were higher than the minimum resolution of UV spectrometer $(0.1 \mathrm{~nm})$. Therefore, solvation and derivatization facilitate effective identification of PAEs and their derivatives. The mechanism for enhancing UV absorption intensities was analyzed using a 2D QSAR model. Quantitative parameters that positively and negatively affected the UV absorption intensities were obtained, and explained the effects of derivatization and solvation on the PAEs. Finally, the $\log K_{\mathrm{ow}}$ values of PAE derivatives were predicted based on a $3 D$ QSAR pharmacophore model of the PAE $\log K_{\text {ow }}$ values. The $\log K_{\text {ow }}$ values of the DNOP derivatives were much lower than those of DNOP, which means they could be more environmentally friendly.

\section{Acknowledgements}

This work was supported by the Fundamental Research Funds for the Central Universities in 2013 (Grant No. JB2013146): Study on Toxicity Control of PBDEs Based on Quantum Chemistry and QSAR Model and supported by the Fundamental Research Funds for the Central Universities in 2017 (grant No. 2017XS058): Study on Enhancement of Vibrational Spectra by Derivation of Phthalic Acid Esters using Pharmacophore Model.

\section{Conflict of Interest}

The authors declare no conflict of interest.

\section{References}

1. LI H.N., ZHU X.P., JIANG Y., NI J.R. Comparative electrochemical degradation of phthalic acid esters using boron-doped diamond and Pt anodes. Chemosphere. 80, (8), 845, 2010.

2. TANG X.Y., WANG S.Y., YANG Y., TAO R., DAI Y.N., A D., LI L. Removal of six phthalic acid esters (PAEs) from domestic sewage by constructed wetlands. Chem. Eng. J. 275, 198, 2015.

3. MENG X.Z., WANG Y., XIANG N., CHEN L., LIU Z.G., WU B., DAI X.H., ZHANG Y.H., XIE Z.Y., EBINGHAUS R. Flow of sewage sludge-borne phthalate esters (PAEs) from human release to human intake: implication for risk assessment of sludge applied to soil. Sci. Total. Environ. 476-477, 242, 2014.

4. EREMINA N., PASCHKE A., MAZLOVA E.A., SCHÜÜRMANN G. Distribution of polychlorinated 
biphenyls, phthalic acid esters, polycyclic aromatic hydrocarbons and organochlorine substances in the Moscow River, Russia. Environ. Pollut. 210, 409, 2016.

5. LIU H., LIANG H.C., LIANG Y., ZHANG D., WANG C., CAI H.S., SHVARTSEV S.L. Distribution of phthalate esters in alluvial sediment: a case study at Jiang Han Plain, Central China. Chemosphere. 78 (4), 382, 2010.

6. MAHMOUD M.A., JOSÉ R.U., RAÚL O.P., JOSÉ D.M.D., MANUEL S.P. Environmental impact of phthalic acid esters and their removal from water and sediments by different technologies-A review. J. Environ. Manage. 109, 164, 2012.

7. YU X.Z., YUE D.M., REN Y.F. Possible mechanisms involved in degradation of phthalic acid esters in the environment. Ecol. Sci. 34 (4), 180, 2015.

8. BEAMES J.M., LIU F., LU L., LESTER M.I. Ultraviolet spectrum and photochemistry of the simplest criegee intermediate CH2OO. J. Am. Chem. Soc. 134 (49), 20045, 2012.

9. TATAUROV A.V., YOU Y., OWCZARZY R. Predicting ultraviolet spectrum of single stranded and double stranded deoxyribonucleic acids. Biophys. Chem. 133 (1-3), 66, 2008.

10. WANG D., CHEN L.S., LIU S.H. Study on the thermodynamic molar absorption coefficient of $\mathrm{Cu}(\mathrm{II})$ Glycine complexes in UV spectrum. Chinese. J. Spectrosc. Lab. 19 (3), 359, 2002.

11. LAU T.K., CHU W., GRAHAM N. The degradation of endocrine disruptor di- $n$-butyl phthalate by UV irradiation: A photolysis and product study. Chemosphere. 60 (8), 1045, 2005.

12. BARRECA S., INDELICATO R., ORECCHIO S., PACE A. Photodegradation of selected phthalates on mural painting surfaces under UV light irradiation. Microchem. J. 114, 192, 2014.

13. BENJAMIN S., PRADEEP S., JOSH M.S., KUMAR S., MASAI E. A monograph on the remediation of hazardous phthalates. J. Hazard. Mater. 298, 58, (15), 2015.

14. LIN T.B. Study and discussion on determination of plasticizer content by ultraviolet spectrophotometry. Chem. Eng. Equip. 12, 154, 2013.

15. QIU Y.L., ZENG Y.L., JIANG L., LI Y. Identification of the Raman characteristic spectrum vibrations for various PAEs based on benzene solvent effect. Chin. J. Lumin. 36 (8), 976, 2015.

16. QU R.J., LIU H.X., FENG M.B., YANG X., WANG Z.Y. Investigation on intramolecular hydrogen bond and some thermodynamic properties of polyhydroxylated anthraquinones. J. Chem. Eng. Data. 57 (9), 2442, 2012.

17. EGGER D.A., LIU Z.F., NEATON J.B. Reliable energy level alignment at physisorbed molecule-metal interfaces from density functional theory. Nano. Lett. 15 (4), 2448, 2015.

18. BANERJEE A.S., ELLIOTT R.S., JAMES R.D. A spectral scheme for Kohn-Sham density functional theory of clusters. J. Comput. Phys. 287, 226, 2015.

19. SOTTILE F., BRUNEVAL F., MARINOPOULOS A.G., DASH L.K., BOTTI S., OLEVANO V., VAST N., RUBIO A., REINING L. TDDFT from molecules to solids: The role of long-range interactions. Int. J. Quantum. Chem. 102 (50), 684, 2005.

20. WANG S., HAO C., GAO Z., CHEN J., QIU J. Effects of excited-state structures and properties on photochemical degradation of polybrominated diphenyl ethers: A TDDFT study. Chemosphere. 88 (1), 33, 2012.
21. CHEN H.B., ZHANG X.H., GONG L Z., HE J., XU X., XU Z. G., LIU H. Y. Effect of $\beta$-substituents on the electronic absorption spectra of manganese(V)-oxo corrole complexes. Acta. Phys-Chim. Sin. 32, 1983, 2016.

22. BARONE V., COSSI M., TOMASI J. Geometry optimization of molecular structures in solution by the polarizable continuum model. J. Comput. Chem. 19 (4), 404, 2015.

23. YUAN Y.Z., HAN R., CAO Q.W., YU J.H., MAO J.L., ZHANG T.F., WANG S.Q., NIU Y.H., LIU D.L. Pharmacophore-based virtual screening of novel inhibitors and docking analysis for CYP51A from penicillium italicum. Mar. Drugs. 15 (4), 107, 2017.

24. JECKSIN O., DENNY K.S., NISHANTH G.C. Optimal molecular design towards an environmental friendly solvent recovery process. Comput. Chem. Eng. 117, 391, 2018.

25. JIANG L., LI Y. Modification of PBDEs (BDE-15, BDE-47, BDE-85 and BDE-126) biological toxicity, bioconcentration, persistence and atmospheric long-range transport potential based on the pharmacophore modeling assistant with the full factor experimental design. J. Hazard. Mater. 307 (16), 202, 2016.

26. HUMBERTO M.F., GELACIO M.G., JORGE E.V. L., JOEL J.T.S., MARTHA S.M.R. Pharmacophore modeling and conformational analysis in the gas phase and in aqueous solution of regioisomeric melatonin analogs. A theoretical and experimental study. J. Mol. Struct. 1133, 534, 2017.

27. QIN L.H., LI X.G., WANG Z.L., YAO W.B., WANG H., XIE X., LONG Y.Q. Pharmacophore model-based design and synthesis of new structure small molecule CCR2 inhibitors. Acta. Chim. Sinica-Chin. Edition. 73, 679, 2015.

28. JIANG L., ZENG Y.L., CAI X.Y., LI Y. Electron transition mechanism of para-halogenated diphenyl ethers based on TD-DFT. Chin .J. Lumin. 35 (5), 627, 2014.

29. JIANG L., QIU Y.L., LI Y. Effects analysis of substituent characteristics and solvents on the photodegradation of polybrominated diphenyl ethers. Chemosphere. 185, 737, 2017.

30. SETHI A., SINGH R.P., SHUKLA D., SINGH P. Synthesis of novel pregnane-diosgenin prodrugs via ring A and ring A connection: A combined experimental and theoretical studies. J. Mol. Struct. 1125, 616, 2016.

31. CHEŁMECKA E., PASTERNY K., KUPKA T., STOBIŃSKI L. DFT studies of COOH tip-functionalized zigzag and armchair single wall carbon nanotubes. J. Mol. Model. 18 (5), 2241, 2012.

32. HUANG H.J., LEE C.C., CHEN C.Y.C. Pharmacological chaperone design for reducing risk factor of Parkinson's disease from traditional chinese medicine. Evid. Based. Complement. Alternat. Med. 2014 (4), 1, 2014.

33. MITTAL A., PALIWAL S., SHARMA M., SINGH A., SHARMA S., YADAV D. Pharmacophore based virtual screening, molecular docking and biological evaluation to identify novel PDE5 inhibitors with vasodilatory activity. Bioorg. Med. Chem. Lett. 24 (14), 3137, 2014.

34. AKINORI H., TOMOHIKO E., EIICHI K., EIJI T., MORIFUSA E. Three-dimensional pharmacophore hypotheses of octopamine receptor responsible for the inhibition of sex-pheromone production in plodiainterpunctella. Int. Electron. J. Mol. Design. 1, 37, 2002.

35. NAYANA R.S., BOMMISETTY S.K., SINGH K., BAIRY S.K., NUNNA S., PRAMOD A., MUTTINENI R. 
Structural analysis of carboline derivatives as inhibitors of MAPKAP K2 using 3D QSAR and docking studies. J. Chem. Inf. Model. 49 (1), 53, 2009.

36. WANG X.L., LI Q., LI M. H., LI Y. Interference adsorption mechanisms of dimethoate, metalaxyl, atrazine, malathion and prometryn in a sediment system containing coexisting pesticides/heavy metals based on fractional factor design (resolution V) assisted by 2D-QSAR. Chem. Res. Chinese U. 34 (3), 397, 2018.

37. LUO Y.F., HUANG J., YU G. QSPR study of vapor pressure of PBDEs by SVM method. Comput. Appl. Chem. 26 (6), 773, 2009.

38. JIANG L., WEN J.Y., ZENG Y.L., LI Y. Investigation on aryl hydrocarbon receptor binding affinity QSAR model of polybrominated diphenyl ethers based on substituent descriptors/quantum chemical parameters. Asian J. Chem. 26 (22), 575, 2014.

39. AROOJ M., THANGAPANDIAN S., JOHN S., HWANG S., PARK J.K., LEE K.W. 3D QSAR pharmacophore modeling, in silico screening, and density functional theory (DFT) approaches for identification of human chymase inhibitors. Int. J. Mol. Sci. 12 (12), 9236, 2011.

40. KHALAF R.A., SHEIKHA G.A., BUSTANJI Y., TAHA M.O. Discovery of new cholesteryl ester transfer protein inhibitors via ligand-based pharmacophore modeling and QSAR analysis followed by synthetic exploration. Eur. J. Med. Chem. 45 (4), 1598, 2010.

41. ZHONG A., ZHANG Y., BIAN Y. Structures and spectroscopic properties of nonperipherally and peripherally substituted metal-free phthalocyanines: A substitution effect study based on density functional theory calculations. J. Mol. Graph. Model. 29 (3), 470, 2010.

42. MORONI L., GELLINI C., SALVI P.R. Thermal denaturation of proteins and chemical equilibrium. World. J. Chem. Educ. 3, 59, 2015.

43. JIANG L., MENG C., LI Y. Study on enhancing characteristic vibration of the molecular vibration spectrum for BDE-15 based on solvent effect. Spectrosc. Spect. Anal. 35 (12), 3459, 2015.

44. ORPHAL J. A critical review of the absorption crosssections of $\mathrm{O}_{3}$ and $\mathrm{NO}_{2}$ in the ultraviolet and visible. J. Photoch. Photobio. A. 157 (2-3), 185, 2003.

45. ZHAO H.M., ZHANG C.Y., GE Z.G., WANG Z.Y. Toxicity (-lgEC50) measurement of the fluorobenzene derivants against vibrio qinghaiensis (Q67) and their 2D, 3D-QSAR study. Chinese. J. Struc. Chem. 29 (10), 1467, 2010.

46. YAO S.W., LOPES V.H.C., FERNÁNDEZ F., GARCÍAMERA X., MORALES M., RODRÍGUEZ B.J.E., CORDEIROA M.N.D.S. Synthesis and QSAR study of the anticancer activity of some novel indane carbocyclic nucleosides. Bioorg. Med. Chem. 11 (23), 4999, 2003.

47. STAPLES C.A., PETERSON D.R., PARKERTON T.F., ADAMS W.J. The environmental fate of phthalate esters: A literature review. Chemosphere. 35 (4), 667, 1997.

48. KELLY B.C., IKONOMOU M.G., BLAIR J.D., MORIN A.E., GOBAS F.A.P.C. Food web-specific biomagnification of persistent organic pollutants. Sci. 317 (5835), 236, 2007. 


\section{Supplementary Tables}

Table S1. Gibbs free energy changes $(\Delta \mathrm{G})$ of the substitution reaction pathways.

\begin{tabular}{|c|c|c|c|}
\hline \multirow{2}{*}{ Reaction paths } & \multicolumn{2}{|c|}{ Gibbs free energy (Hartree) } & \multirow{2}{*}{$\Delta \mathbf{G}(\mathrm{kJ} / \mathbf{m o l})$} \\
\hline & For reactant & For product & \\
\hline Path1 (DMP substituted by -Br) & -3258.84 & -3258.97 & -356.62 \\
\hline Path 2 (DMP substituted by- $\mathrm{CH}_{2} \mathrm{CH}_{3}$ ) & -766.31 & -766.44 & -349.52 \\
\hline Path 3 (DMP substituted by-Cl) & -1147.33 & -1147.46 & -339.68 \\
\hline Path 4 (DMP substituted by- $\mathrm{NO}_{2}$ ) & -892.27 & -892.36 & -230.24 \\
\hline Path 5 (DMP substituted by- $\mathrm{OCH}_{3}$ ) & -802.22 & -802.35 & -348.62 \\
\hline Path 6 (DMP substituted by-SH) & -1085.93 & -1086.05 & -293.85 \\
\hline Path 7 (DBP substituted by-Br) & -3494.58 & -3494.71 & -357.17 \\
\hline Path 8 (DBP substituted by- $\mathrm{CH}_{2} \mathrm{CH}_{3}$ ) & -1002.04 & -1002.18 & -349.08 \\
\hline Path 9 (DBP substituted by-Cl) & -1383.07 & -1383.20 & -341.18 \\
\hline Path 10 (DBP substituted by- $\mathrm{OCH}_{3}$ ) & -1037.96 & -1038.08 & -322.10 \\
\hline Path 11 (DBP substituted by-SH) & -1321.67 & -1321.77 & -268.63 \\
\hline Path 12 (DNOP substituted by- $\mathrm{CH}_{2} \mathrm{CH}_{3}$ ) & -1316.35 & -1316.48 & -348.40 \\
\hline Path 13 (DNOP substituted by- $\mathrm{NO}_{2}$ ) & -1442.31 & -1442.40 & -230.22 \\
\hline Path 14 (DNOP substituted by-SH) & -1635.98 & -1636.09 & -290.46 \\
\hline
\end{tabular}

Table S2. Minimum differential wave numbers for the ultraviolet spectra of phthalic acid esters and their derivatives.

\begin{tabular}{|c|c|c|c|c|c|}
\hline Compounds & $\lambda_{\max }(\mathrm{nm})$ & $\begin{array}{c}\text { Minimum differential wave } \\
\text { number }(\mathrm{nm})\end{array}$ & Compounds & $\lambda_{\text {max }}(\mathrm{nm})$ & $\begin{array}{c}\text { Minimum differential wave } \\
\text { number }(\mathrm{nm})\end{array}$ \\
\hline DMP & 268.37 & 0.09 & DMP-Br & 298.58 & 26.50 \\
\hline DBP & 269.39 & 0.17 & DMP- $\mathrm{CH}_{2} \mathrm{CH}_{3}$ & 280.73 & 7.13 \\
\hline DNOP & 263.51 & 0.40 & DMP-Cl & 286.08 & 12.47 \\
\hline BBP & 273.61 & 2.63 & DMP-NO ${ }_{2}$ & 272.99 & 0.61 \\
\hline BMPP & 263.90 & 0.39 & $\mathrm{DMP}^{-} \mathrm{OCH}_{3}$ & 235.69 & 5.34 \\
\hline DEHP & 270.98 & 0.78 & DMP-SH & 240.81 & 14.04 \\
\hline DHP & 266.66 & 0.01 & $\mathrm{DBP}-\mathrm{Br}$ & 298.09 & 24.48 \\
\hline DIBP & 263.11 & 0.40 & $\mathrm{DBP}-\mathrm{CH}_{2} \mathrm{CH}_{3}$ & 280.25 & 6.64 \\
\hline DIDP & 269.23 & 0.17 & DBP-Cl & 285.67 & 12.07 \\
\hline DIHxP & 254.86 & 7.06 & $\mathrm{DBP}-\mathrm{OCH}_{3}$ & 219.29 & 35.57 \\
\hline DINP & 270.20 & 0.78 & DBP-SH & 240.19 & 14.67 \\
\hline DIPrP & 261.91 & 1.20 & $\mathrm{DNOP}-\mathrm{CH}_{2} \mathrm{CH}_{3}$ & 275.11 & 1.50 \\
\hline DNP & 265.63 & 1.03 & $\mathrm{DNOP}_{-} \mathrm{NO}_{2}$ & 277.51 & 3.90 \\
\hline DPP & 266.67 & 0.01 & DNOP-SH & 238.50 & 16.36 \\
\hline DPrP & 268.45 & 0.09 & & & \\
\hline DEP & 272.08 & 1.10 & & & \\
\hline
\end{tabular}


Table S3. $\log K_{o w}$ values of 15 PAEs predicted using the Hypo1 model.

\begin{tabular}{|c|c|c|c|c|c|}
\hline No. & PAEs & Fit value & Pred $\log K_{\text {ow }}$ & Act $\log K_{\text {ow }}$ & Error \\
\hline $1^{\mathrm{a}}$ & DMP & 5.85 & 1.88 & 1.61 & 1.16 \\
\hline $2^{\mathrm{a}}$ & DPrP & 5.59 & 3.36 & 3.27 & 1.03 \\
\hline $3^{\mathrm{a}}$ & DAP & 5.49 & 4.25 & 3.23 & 1.32 \\
\hline $4^{a}$ & DEP & 5.47 & 4.45 & 2.38 & 1.87 \\
\hline $5^{\mathrm{a}}$ & DBP & 5.43 & 4.84 & 4.45 & 1.09 \\
\hline $6^{\mathrm{a}}$ & DHP & 5.38 & 5.52 & 6.30 & -1.14 \\
\hline $7^{\mathrm{a}}$ & DNOP & 5.35 & 5.83 & 8.06 & -1.38 \\
\hline $8^{\mathrm{a}}$ & DEHP & 5.34 & 5.97 & 7.50 & -1.26 \\
\hline $9^{a}$ & BBP & 5.34 & 6.04 & 4.59 & 1.32 \\
\hline $10^{\mathrm{a}}$ & DIDP & 5.27 & 7.04 & 10.30 & -1.46 \\
\hline $11^{\mathrm{a}}$ & DINP & 5.26 & 7.24 & 9.00 & -1.24 \\
\hline $12^{\mathrm{a}}$ & DTDP & 5.20 & 8.27 & 13.40 & -1.62 \\
\hline $13^{\mathrm{b}}$ & DIBP & 5.18 & 8.65 & 11.50 & -1.33 \\
\hline $14^{\mathrm{b}}$ & DIOP & 5.23 & 7.78 & 8.00 & -1.03 \\
\hline $15^{\mathrm{b}}$ & DUP & 5.34 & 6.00 & 4.11 & 0.68 \\
\hline
\end{tabular}

$a$, training set. $b$, test set 